Fabian Schmid, Frank Behrendt

\title{
Optimal sizing of Solar Home Systems: Charge controller technology and its influence on system design
}

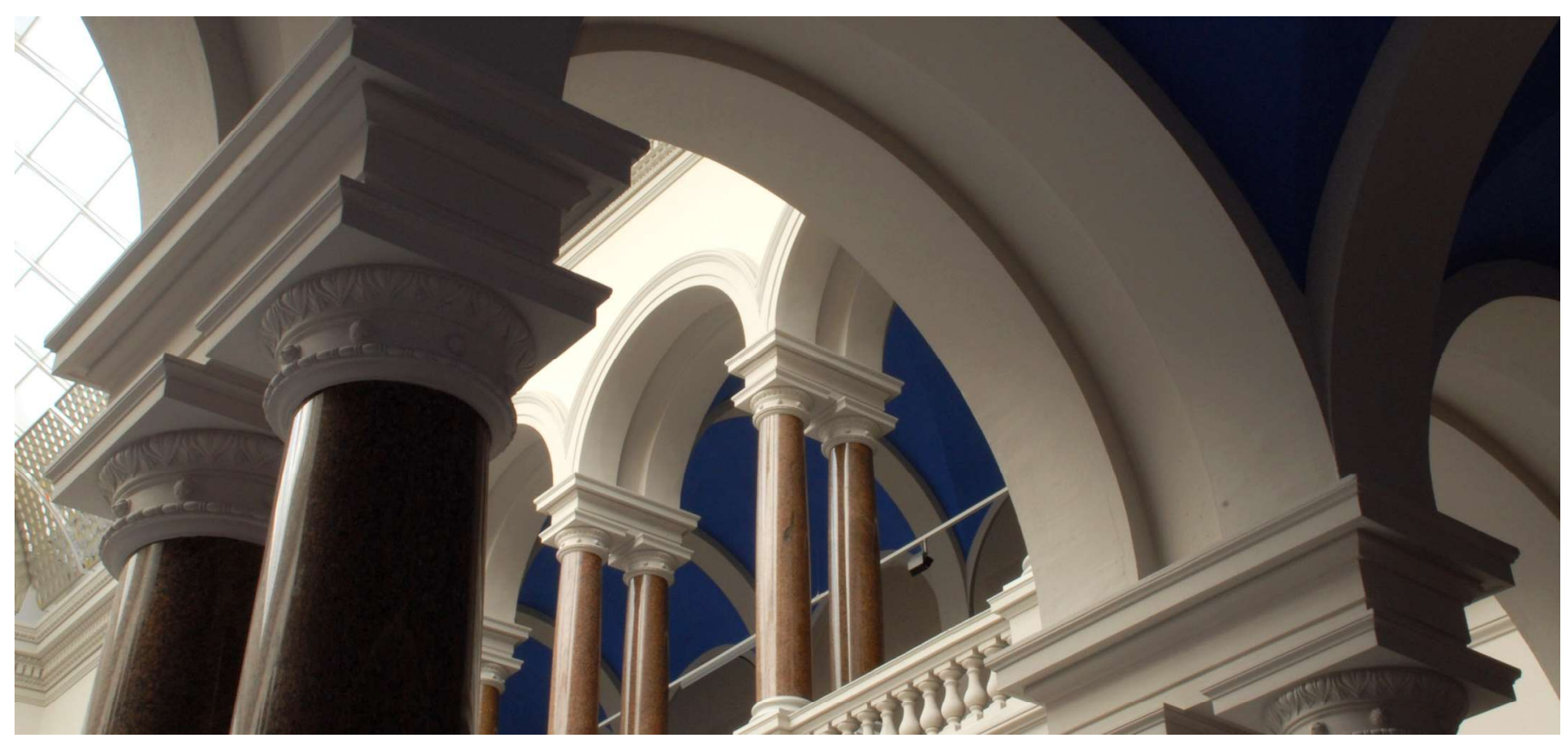

Schmid, F., \& Behrendt, F. (2021). Optimal sizing of Solar Home Systems: Charge controller technology and its influence on system design. Sustainable Energy Technologies and Assessments, 45, 101198. https://doi.org/10.1016/j.seta.2021.101198 


\title{
Optimal Sizing of Solar Home Systems: Charge Controller Technology and Its Influence on System Design
}

\author{
Fabian Schmid a, email: fabian.schmid@tu-berlin.de
}

Prof. Dr. Frank Behrendt a , email: frank.behrendt@tu-berlin.de

a) Technische Universität Berlin, Institute for Energy Engineering, Chair for Energy Process Engineering and Conversion Technologies for Renewable Energies, Strasse des 17. Juni 135, 10623 Berlin, Germany

\section{HIGHLIGHTS}

- Optimal Solar Home System sizing based on multi-objective optimization

- Influence of charge controller technology on system sizing and life cycle costs

- Maximum Power Point Tracker achieves cost savings of $4.0 \%$ to $8.6 \%$

- Results show high robustness regarding irradiance, load profile, and economic variation

\begin{abstract}
Solar Home Systems are a promising solution to enable access to affordable, reliable, sustainable, and modern energy for non-electrified areas, especially in the Global South. In this study, the influence of the charge controller technologies Maximum Point Tracker (MPPT) and Pulse Width Modulation (PWM) on the optimal system design and system performance is analyzed. Therefore, a multi-objective optimization that minimizes the number of days with Power-Cut-Offs and the Levelized Cost of Electricity for three Solar Home System sizes and three sub-saharan locations is conducted. Cost savings of the MPPT controller are in the range of $4.0 \%$ to $8.6 \%$ compared to the PWM controller. This is achieved by a reduction of the optimal installed photovoltaic peak power by $31.2 \%$ to $38.6 \%$ and the battery capacity by $2.8 \%$ to $8.8 \%$. A sensitivity analysis shows the high robustness of cost savings regarding a variation in solar irradiance, load profile, and charge controller investment costs. Therefore, MPPT charge controllers are a promising solution even for the smallest Solar Home System sizes to reduce system costs compared to PWM controllers. The applied numerical simulation tool is open-source to enhance openness and transparency in modeling studies.
\end{abstract}

\section{KEYWORDS}

- Solar Home Systems

- System sizing

- Multi-objective optimization

- Charge controller technology

- Open-source simulation tool

Accepted manuscript of: Schmid, F., \& Behrendt, F. (2021). Optimal sizing of Solar Home Systems: Charge controller technology and its influence on system design. Sustainable Energy Technologies and Assessments, 45, 101198. https://doi.org/10.1016/j.seta.2021.101198

(C) 2020. This manuscript version is made available under the CC-BY-NC-ND 4.0 license http://creativecommons.org/licenses/by-nc-nd/4.0/ 
NOMENCLATURE

\begin{tabular}{|c|c|}
\hline \multicolumn{2}{|l|}{ Introduction } \\
\hline SHS & Solar Home Systems \\
\hline PWM & Pulse Width Modulation \\
\hline MPPT & Maximum Power Point Tracker \\
\hline PCO & Power-Cut-Offs \\
\hline LCoE & Levelized Cost of Electricity \\
\hline \multicolumn{2}{|c|}{ Methodology - Photovoltaic model } \\
\hline PV & Photovoltaic \\
\hline DC & Direct current \\
\hline I & Photovoltaic current $[\mathrm{A}]$ \\
\hline $\mathrm{I}_{\mathrm{L}}$ & Photovoltaic light current $[\mathrm{A}]$ \\
\hline $\mathrm{I}_{\mathrm{D}}$ & Photovoltaic diode current $[A]$ \\
\hline $\mathrm{I}_{\mathrm{sh}}$ & Photovoltaic shunt current $[\mathrm{A}]$ \\
\hline $\mathrm{I}_{0}$ & Photovoltaic diode reverse saturation current $[A]$ \\
\hline $\mathrm{V}$ & Photovoltaic voltage [V] \\
\hline $\mathrm{R}_{\mathrm{s}}$ & Photovoltaic series resistance $[\Omega]$ \\
\hline $\mathrm{R}_{\mathrm{sh}}$ & Photovoltaic shunt resistance $[\Omega]$ \\
\hline a & Photovoltaic modified ideality factor \\
\hline $\mathrm{N}_{\mathrm{s}}$ & Photovoltaic number of cells in series \\
\hline $\mathrm{n}_{1}$ & Photovoltaic usual ideality factor \\
\hline k & Boltzmann's constant \\
\hline$q$ & Electron charge \\
\hline $\mathrm{T}_{\mathrm{c}}$ & Photovoltaic cell temperature [K] \\
\hline$P_{P W M}, P V$ & Photovoltaic output power with PWM controller [W] \\
\hline$V_{\text {battery }}$ & Battery voltage $[\mathrm{V}]$ \\
\hline $\mathrm{P}_{\mathrm{MPPT}}$, PV & Photovoltaic output power with MPPT controller [W] \\
\hline $\mathrm{G}_{\text {poa }}$ & Total plane of array irradiance $\left[\mathrm{W} \cdot \mathrm{m}^{-2}\right]$ \\
\hline $\mathrm{G}_{\mathrm{STC}}$ & Solar irradiance at Standard Test Conditions $\left[\mathrm{W} \cdot \mathrm{m}^{-2}\right]$ \\
\hline$P_{\text {dco }}$ & Photovoltaic peak output power [Wp] \\
\hline$\gamma_{\mathrm{pdc} 0}$ & Photovoltaic temperature coefficient of $\mathrm{P}_{\mathrm{dc} 0}\left[1 \cdot \mathrm{K}^{-1}\right]$ \\
\hline $\mathrm{T}_{\text {Cell }}$ & Photovoltaic cell temperature $[\mathrm{K}]$ \\
\hline $\mathrm{T}_{\mathrm{STC}}$ & Temperature at Standard Test Conditions [K] \\
\hline $\mathrm{V}_{\text {wind }}$ & Wind speed $\left[\mathrm{m} \cdot \mathrm{s}^{-1}\right]$ \\
\hline $\mathrm{T}_{\mathrm{a}}$ & Ambient temperature $[\mathrm{K}]$ \\
\hline \multicolumn{2}{|c|}{ Methodology - Power Component model } \\
\hline$P_{\text {out }}$ & Power component output power [W] \\
\hline$\eta$ & Power component efficiency \\
\hline$p_{\text {self }}$ & Power component parameter referred to non-performance-related self-consumption \\
\hline Vloss & Power component parameter referred to voltage losses over diodes and transistors \\
\hline rloss & Power component parameter referred to ohmic losses \\
\hline$P_{\text {in }}$ & Power component input power [W] \\
\hline \multicolumn{2}{|c|}{ Methodology - Battery model } \\
\hline$\eta_{\mathrm{CH}}$ & Battery charge efficiency \\
\hline$\eta_{\mathrm{DCH}}$ & Battery discharge efficiency \\
\hline SoC & Battery state of charge \\
\hline SoC $_{\text {cut off, } \mathrm{CH}}$ & Battery state of charge end of charge boundary \\
\hline SoC cut off, DCH & Battery state of charge end of discharge boundary \\
\hline $\mathrm{V}_{\mathrm{CH}}$ & Battery voltage during charge [V] \\
\hline $\mathrm{V}_{\mathrm{DCH}}$ & Battery voltage during discharge [V] \\
\hline $\mathrm{P}_{\mathrm{T}}$ & Battery terminal power [W] \\
\hline$P_{\text {loss, total }}$ & Battery charge and discharge losses [W] \\
\hline$P_{\text {self-discharge }}$ & Battery self-discharge power [W] \\
\hline $\mathrm{dt}$ & Simulation timestep [h] \\
\hline$E_{\text {actual }}$ & Battery capacity at simulation timestep [Wh] \\
\hline $\mathrm{T}_{\mathrm{b}}$ & Battery cell temperature $[\mathrm{K}]$ \\
\hline h & Battery heat transfer coefficient $\left[\mathrm{W} \cdot \mathrm{m}^{-2} \cdot \mathrm{K}^{-1}\right]$ \\
\hline A & Battery surface-specific energy [Wh·m-2] \\
\hline $\mathrm{m}$ & Battery mass-specific energy $\left[\mathrm{Wh} \cdot \mathrm{kg}^{-1}\right]$ \\
\hline$C_{p}$ & Battery average heat capacity $\left[\mathrm{J} \cdot \mathrm{kg}^{-1} \cdot \mathrm{K}^{-1}\right]$ \\
\hline cycle life & Battery cycle life \\
\hline DoD & Battery depth of discharge \\
\hline
\end{tabular}




\begin{tabular}{|c|c|}
\hline cycle life micro-cycle & Battery cycle life of micro-cycle \\
\hline$\overline{\mathrm{DOD}}$ & Battery mean depth of discharge of micro-cycle \\
\hline $\mathrm{C}_{\text {relative loss, micro-cycle }}$ & Battery relative capacity degradation of micro-cycle \\
\hline$E_{\text {micro-cycle }}$ & Energy cycled during a battery micro-cycle $[\mathrm{Wh}]$ \\
\hline$C_{\text {nominal }}$ & Battery nominal capacity [Wh] \\
\hline Cend of life & Battery end of life capacity [Wh] \\
\hline Closs, micro-cycle & Battery absolute capacity degradation of micro-cycle due to cycling aging [Wh] \\
\hline calendric life & Battery float lifetime [a] \\
\hline Closs, calendric & Battery absolute capacity degradation due to calendric aging [Wh] \\
\hline \multicolumn{2}{|c|}{ Methodology-Economic model } \\
\hline CC & Component investment costs \\
\hline OMC & Component operation and maintenance costs \\
\hline BOS & Balance of System costs \\
\hline ATLCC & Annual levelized cost flow $\left[\$ \cdot a^{-1}\right]$ \\
\hline$E_{\text {load supplied }}$ & Supplied load energy [Wh] \\
\hline$A_{c c, k}$ & Annuity of investment costs of component $k\left[\$ \cdot a^{-1}\right]$ \\
\hline$A_{o m c, k}$ & Annuity of the operation and maintenance costs of component $\mathrm{k}\left[\$ \cdot \mathrm{a}^{-1}\right]$ \\
\hline$A_{r c, k}$ & Annuity of replacement costs of component $k\left[\$ \cdot a^{-1}\right]$ \\
\hline$A_{r v, k}$ & Annuity of residual costs of the component $k\left[\$ \cdot a^{-1}\right]$ \\
\hline CRF & Capital recovery factor \\
\hline SoD $D_{k, t}$ & State of destruction of component $\mathrm{k}$ at the time $\mathrm{t}$ \\
\hline $\mathrm{i}_{\text {eff }}$ & Annual percentage rate \\
\hline HV & Hypervolume/Hyperarea \\
\hline GD & Generational Distance \\
\hline IGD & Inverted Generational Distance \\
\hline \multicolumn{2}{|l|}{ Results } \\
\hline $\mathrm{PSH}$ & Peak Sun Hours \\
\hline
\end{tabular}




\section{INTRODUCTION}

The Sustainable Development Goal 7 aims to ensure access to affordable, reliable, sustainable, and modern energy for the world population. In 2018 global electrification rate reached $90 \%$ but remains lowest in subsaharan africa with $47 \%$. Under current policies, it is estimated, that about 620 million people will not have access to energy in 2030, of which $85 \%$ will be in sub-saharan africa [1]. Off-grid solar systems have a high potential to tackle this problem by improving greenhouse gas emissions, economic opportunities, private savings, health risks, and energy services compared to traditional fossil-based energy solutions [2]. They can be implemented in non-electrified rural areas and in grid-connected urban areas, which in sub-saharan africa are increasingly suffering from frequent power shortages and outages [3]. Indeed, off-grid solar systems are proving to be the leapfrog infrastructure of the current decade [4].

According to the Off-Grid Solar Market Trends Report 2020, off-grid solar household products can be categorized into Portale Lanterns for lighting purposes only, Multi-light Systems with multiple light sources and mobile charging possibilities, and Solar Home Systems. Solar Home Systems (SHS) are further categorized into 'Entry level' (11-20.99 Wp), 'Basic capacity' (21-49.99 Wp), 'Medium capacity' (50-99.99 Wp), and 'Higher capacity' (> $100 \mathrm{Wp}$ ) [5]. Lightning Global lists up-to-date SHS products, which meet their quality standard according to the IEC TS 62257-9-5:2018 [6], to set a baseline level of product quality and durability [7].

SHS normally consist of different direct current appliances, a photovoltaic panel, a charge controller, and a storage technology to buffer the fluctuating solar resource and to provide energy also during night and days with lower solar irradiation. Different battery technologies exist for usage in SHS. They differ in their technical, ecological, and economic performance [8]. Lead-acid and lithium-ion battery technologies are dominantly used in SHS applications [9]. Charles et al. state that lead-acid batteries are readily available at low cost and are the current best choice for sustainable small-scale domestic photovoltaic systems [8]. While lead-acid batteries and their lifetime prediction are examined extensively (e.g. May et al. [10], Sauer et al. [11], and Narayan et al. [12]), studies focusing on the charge controller technology and its influence on optimal system sizing and performance are rare. Charge controllers protect and control the battery charge and discharge process and specify the photovoltaic operating point with its voltage level and therewith influence the photovoltaic energy yield. Two general types of charge controller exist; Pulse Width Modulation (PWM) and Maximum Power Point Tracker (MPPT). Laguado-Serrano et al. do an experimental comparison of these two charge controller types and measure the voltage and current levels in photovoltaic and battery to determine controller efficiency. They state that PWM charge controllers have certainly a lower efficiency but are an option with a lower price in relation to the MPPT [13]. This statement is in accordance with a whitepaper by a manufacturer of off-grid solar solutions, which states that PWM charge controllers are a good low-cost solution for small systems only [14]. Müller et al. provide an analysis of MPPT charge controller design and efficiency in photovoltaic off-grid systems, including the application in SHS, and state that MPPT charge controllers offer a wider choice of photovoltaic panels even with more than 36 or 72 cells [15].

SHS sizing is a complex task due to an uncertain load profile and fluctuating solar resources. Both, over- and undersizing of a system have negative effects on system cost and reliability. Campana et al. present an opensource Visual Basic for Applications optimization tool for SHS component sizing and identify incorrectly sized systems in a case study in Namibia. Authors provide static optimal component sizing, at randomly selected performance metrics of one day of autonomy and reliability of $99.9 \%$. The tool further uses static component efficiency values and neglects battery degradation [16]. Rossi et al. compare the economic and environmental optimal design of grid-connected Solar Home Systems using a mixed-integer linear programming approach with an innovative cross-evaluation analysis [17]. The case-study covers an application in Italy with higher SHS capacities as introduced by [5]. Khatib et al. propose an artificial-intelligence-based standalone photovoltaic system sizing method. They use multi-objective optimization based on the objective functions loss of load probability and the life cycle costs and state that methods can successfully be used in the sizing process of such kind of systems [18]. Narayan et al. describe a genetic algorithm-based multi-objective optimization with four objectives for SHS sizing minimizing loss of load probability, excess energy, and battery size, while maximizing the battery lifetime [19]. For optimization problems involving more than three objective functions, Chen et al. propose an innovative many-objective population extremal optimization method, which outperforms state-ofthe-art evolutionary algorithms tested for a DTLZ test problem [20] and other recent algorithm enhancements [21]. Mentioned sizing studies focusing on photovoltaic stand-alone systems in [18], [19] highlight that genetic algorithms are a powerful and appropriate method for the case of SHS. But there is a clear research gap in the 
literature concerning studies focusing on the influence of charge controller technology on optimal SHS sizing. Further detailed open-source numerical simulation models for optimal sizing of SHS could not be identified.

In this study, three SHS size categories at three locations of the main sub-saharan markets are analyzed using a state-of-the-art multi-objective genetic algorithm. The main contributions of this paper are:

1. An open-source numerical simulation tool for optimal SHS sizing is proposed that provides Paretooptimal solutions with a minimal number of days with Power-Cut-Offs (PCO) and Levelized Cost of Electricity (LCOE).

2. The influence of charge controller technology on Pareto-optimal solutions and system sizing is analyzed.

3. A sensitivity analysis provides insight into the robustness of obtained simulation results and influencing parameters.

The methodology of this work with the developed mathematical component models, case studies analyzed, and methods applied are introduced in chapter 2 . In chapter 3 the main findings of the multi-objective optimization and sensitivity analysis are presented and discussed. The authors finish the paper with conclusions on the influence of charge controller technology on SHS sizing and an outlook of future work.

\section{METHODOLOGY}

This section describes the mathematical and economic models for the numerical simulation. Component energy dissipation and degradation are considered as they have a high influence on the system performance and sizing process. Meteorological and load input data for the case studies analyzed is described. The implementation of the simulation model, multi-objective optimization, and sensitivity analysis is explained.

Figure 1 displays the considered direct current (DC) based SHS system with photovoltaic (PV) panel, charge controller, lead-acid battery, and DC loads.

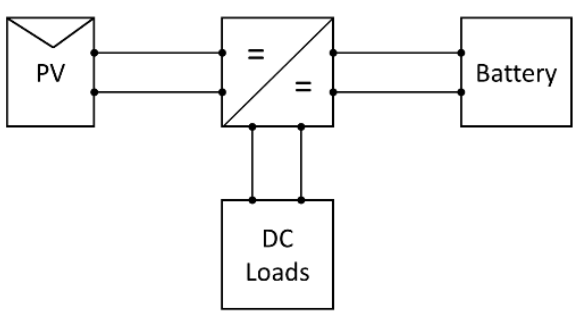

Figure 1 Representation of considered SHS system configuration.

\subsection{Mathematical model}

This section describes the used mathematical models of all technical system components and the used simulation input data.

\subsubsection{Photovoltaic model}

The photovoltaic model consists of a power model, thermal model, and a simple degradation model. For its implementation, the pvlib library version 0.7.1 is used [22]. Utilized photovoltaic modules are the Pythagoras Solar Midi PVGU Window, Canadian Solar Inc. CS5C-80M, and Resonix EPML120W6Hall [23]-[25]. These modules show all a reasonable voltage level for the usage with a PWM charge controller and a nominal peak power in accordance with the considered system sizes (compare section 2.1.4). The meteorological input data with the considered photovoltaic inclination and orientation is described in section 2.1.5.

\section{Power model}

The photovoltaic power model computes the photovoltaic output power depending on the used charge controller technology. In the case of a PWM charge controller, the photovoltaic output power needs to be calculated at a specific voltage point. Therefore, the current-voltage relationship following the single-diode five parameter model by De Soto et al. is implemented [27]. The model is based on manufacturer datasheet information (compare Table 1), the absorbed solar irradiation, and the cell temperature together with semiempirical equations. Datasheet information can be obtained from the CEC module database, which is available 
on the National Renewable Energy Laboratory GitHub website [26]. The model is also used in the System Advisor Model software and described in detail in [28]. The following equations define the basic relationship of the singlediode model:

$$
\begin{aligned}
& I=I_{L}-I_{D}-I_{S h} \\
& I=I_{L}-I_{0} \cdot\left(e^{\frac{V+I \cdot R_{S}}{a}}-1\right)-\frac{V+I \cdot R_{S}}{R_{S h}}
\end{aligned}
$$

with $I_{L}$ the light current in $A, I_{D}$ the diode current in $A, I_{s h}$ the shunt current in $A$, $I_{0}$ the diode reverse saturation current in $A, V$ the photovoltaic voltage in $V, R_{s}$ the series resistance in $\Omega, R_{s h}$ the shunt resistance in $\Omega$ and a the modified ideality factor. This factor is defined by the following equation:

$$
a=\frac{N_{s} \cdot n_{I} \cdot k \cdot T_{c}}{q}
$$

with $\mathrm{N}_{\mathrm{s}}$ the number of cells in series, $\mathrm{n}_{\mathrm{I}}$ the usual ideality factor, $\mathrm{k}$ the Boltzmann's constant $\left(1.38066 \cdot 10^{-23} \mathrm{~J} \cdot \mathrm{K}^{-1}\right)$, $\mathrm{q}$ the electron charge and $T_{c}$ the photovoltaic cell temperature in $\mathrm{K}$.

The photovoltaic output power can then be calculated at a specific voltage point of the obtained current-voltage relationship with the product of voltage and current. It is assumed that the photovoltaic panel works at the battery voltage (compare section 2.1.3) and voltage losses due to cabling between battery and photovoltaic panel are neglected.

$$
P_{P W M, P V}=I \cdot V_{\text {battery }}
$$

In the case of a MPPT charge controller, it is assumed that the photovoltaic panel always works at its Maximum Power Point. Tracking losses are neglected. The model is based on the PVWatts Version 5 model (included in the used pvlib library version 0.7.1) and is defined by the following equation [29]:

$$
P_{M P P, P V}=\frac{G_{p o a}}{G_{S T C}} \cdot\left(P_{d c 0} \cdot\left(1+\gamma_{p d c 0} \cdot\left(T_{c}-T_{S T C}\right)\right)\right)
$$

with $\mathrm{G}_{\text {poa }}$ the total plane of array irradiance in $\mathrm{W} \cdot \mathrm{m}^{-2}, \mathrm{Gstc}$ the irradiance at Standard Test Conditions $\left(1000 \mathrm{~W} \cdot \mathrm{m}^{-}\right.$ $\left.{ }^{2}\right), P_{d c o}$ the photovoltaic peak output power at the Maximum Power Point and Standard Test Conditions in Wp, $\gamma_{p d c o}$ the temperature coefficient of the output power in $1 \cdot \mathrm{K}^{-1}, \mathrm{~T}_{\mathrm{c}}$ the variable photovoltaic cell temperature in $\mathrm{K}$ and $T_{\text {STC }}$ the temperature at Standard Test Conditions (298.15 K).

Relevant parameters and constants used for the photovoltaic model can be found in Table 1.

Table 1 Photovoltaic model parameter based on following modules [23]-[25] obtained from the CEC module list from [26].

\begin{tabular}{lllll}
\hline Parameter & Unit & Pico System & Medium System & Large System \\
\hline Photovoltaic & & Pythagoras Solar & Canadian Solar Inc. & Resonix \\
panel type & & Midi PVGU Window & CS5C-80M & EPML120W6H \\
Pdc0 $_{\text {V }}$ & Wp & 20.3 & 80.2 & 121.5 \\
$V_{\text {mp }}$ & $\mathrm{V}$ & 16.1 & 17.5 & 16.2 \\
$\mathrm{a}$ & & 0.795311 & 0.976234 & 0.822578 \\
$\mathrm{IL}$ & $\mathrm{A}$ & 1.351524 & 4.980938 & 8.117732 \\
$\mathrm{I}_{\mathrm{o}}$ & $\mathrm{A}$ & $3.37 \cdot 10^{-11}$ & $6.69 \cdot 10^{-10}$ & $2.17 \cdot 10^{-10}$ \\
$\mathrm{R}_{\mathrm{sh}}$ & $\Omega$ & 633.18 & 148.16 & 82.86 \\
$\mathrm{R}_{\mathrm{s}}$ & $\Omega$ & 0.714915 & 0.326085 & 0.181393 \\
$\gamma_{\mathrm{pdc}}$ & $1 \cdot \mathrm{K}^{-1}$ & -0.005 & -0.005 & -0.005 \\
\hline
\end{tabular}

\section{Thermal model}

The photovoltaic thermal model computes the cell temperature dependent on environmental conditions as solar irradiance, ambient temperature, and wind speed. The semi-empirical approach by King et al. is used [30]. The equation consists of two terms, from which the first describes the temperature of the photovoltaic module, while the second defines the temperature difference between the module and the cell itself. The following equation describes the thermal model: 


$$
T_{c}=\left(G_{p o a} \cdot \exp ^{a+b \cdot v_{\text {Wind }}}+T_{a}\right)+\Delta T \cdot \frac{G_{p o a}}{G_{S T C}}
$$

with $G_{\text {poa }}$ the total plane of array irradiance in $\mathrm{W} \cdot \mathrm{m}^{-2}, \mathrm{v}_{\text {wind }}$ the wind speed in $\mathrm{m} \cdot \mathrm{s}^{-1}, \mathrm{~T}_{\mathrm{a}}$ the ambient temperature in $\mathrm{K}$, and the empiric parameters for a glass/cell/polymer sheet module type with an open rack mounting, which are $a=-3.56, b=-0.075$ and $\Delta \mathrm{T}=3[30]$.

\section{Degradation model}

To include the proceeding degradation of a photovoltaic module and to determine the component state of destruction an annual degradation rate of the peak power of $0.5 \% \cdot a^{-1}$ is assumed in this study. This value corresponds to Linssen et al. [31].

\subsubsection{Electronic model}

The electronic model consists of a power model which defines the electronic component efficiency and a lifetime model.

\section{Power model}

The power model follows the approach by Sauer and Schmidt, which describes the power-dependent efficiency of photovoltaic inverters [32]. Its basic equation is:

$$
\eta\left(P_{\text {out }}\right)=\frac{P_{\text {out }}}{P_{\text {out }}+\left(p_{\text {self }}+v_{\text {loss }} \cdot P_{\text {out }}+r_{\text {loss }} \cdot P_{\text {out }}\right)}
$$

with $\mathrm{P}_{\text {out }}$ the component output power in $\mathrm{W}$ and the model coefficients $\mathrm{p}_{\text {self, }} \mathrm{V}_{\text {loss, }}$ and $\mathrm{r}_{\text {loss. }}$ The efficiency equation can also be defined depending on the component input power with the coefficients $p_{\text {self }}{ }^{*}$, Vloss ${ }^{*}$ and rloss ${ }^{*}$ :

$$
\eta\left(P_{\text {in }}\right)=-\frac{1}{2 \cdot r_{\text {loss }}^{*} \cdot P_{\text {in }}}+\sqrt{\frac{\left(1+v_{\text {loss }}^{*}\right)^{2}}{\left(2 \cdot r_{\text {loss }}^{*} \cdot P_{\text {in }}\right)^{2}}+\frac{p_{\text {in }}+p_{\text {self }}^{*}}{r_{\text {loss }}^{*} \cdot P_{\text {in }}{ }^{2}}}
$$

The model coefficients $p_{\text {self, }}$ Vloss, and loss are parametrized with power-dependent efficiency curves of the power component provided in most datasheets. Equations for the coefficient transformation are given in [32].

The MPPT charge controller is parametrized with the datasheet information of the HQST MPPT Solar Charge Controller [33]. Power-dependent efficiency curves of PWM charge controllers could not be identified. It is further dependent on the switching frequency, which correlates with the battery charge level. Therefore, the power-dependent efficiency curve is estimated with the assumption of a mean switching cycle. The obtained efficiency curves of the PWM and MPPT charge controller lie slightly above the mean values of the study by Laguado et al., which compares the performance of these two types of charge controller [13]. Figure 2 presents the used power-dependent efficiency curves of both charge controller technologies, Table 2 shows the identified model parameters.

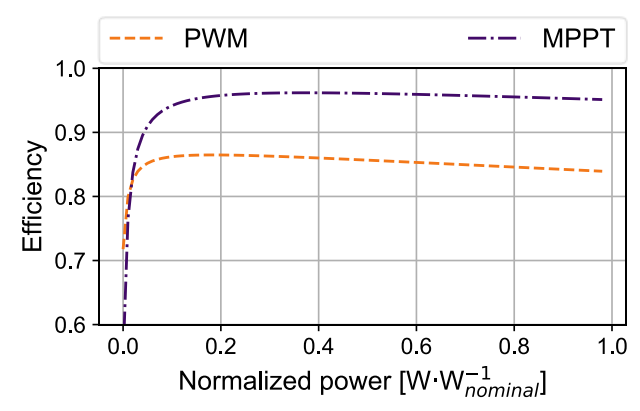

Figure 2: Power-dependent efficiency curves of considered charge controller technologies.

Table 2 Model parameter of considered charge controller technologies [34].

\begin{tabular}{lllll}
\hline Component & $\boldsymbol{p}_{\text {self }}$ & $\boldsymbol{v}_{\text {loss }}$ & $\boldsymbol{r}_{\text {loss }}$ & $\boldsymbol{\eta}_{\text {nominal }}$ \\
\hline MPPT & 0.002671 & 0.009737 & 0.031432 & 0.951 \\
PWM & 0.002212 & 0.134184 & 0.055497 & 0.839 \\
\hline
\end{tabular}




\section{Lifetime model}

For the charge controller, a lifetime of 10 years without dynamic power degradation is assumed, from which the component state of destruction can be calculated.

\subsubsection{Battery model}

The battery model consists of a state model, which defines charge and discharge efficiencies, cut-off boundaries, state of charge and voltage, a thermal model, and a degradation model, which computes the capacity loss due to calendric and cycle aging. A lead-acid battery is considered as it is a low-cost and readily available storage technology [8]. The model is parametrized with the battery Ritar OPzV 100, which is a $12 \mathrm{~V}$ battery with a $100 \mathrm{Ah}$ capacity [35].

\section{State model}

The power-dependent charge and discharge efficiencies and cut-off boundaries are based on the method presented by Schmid et al. [36]. The model assumes a simple equivalent circuit with a power-dependent resistance for the charge and discharge process. The model is parametrized with the fitted battery charge and discharge curves (voltage-state of charge (SoC) correlation) at different C-rates, using the mathematical formulation by Tremblay et al. [37]. Applying the ohmic law the internal resistance of the cell can be determined with curves at different C-rates and therewith the efficiency of the battery cell. Following linear equations describe the charge and discharge efficiencies:

$$
\begin{aligned}
& \eta_{C H}(C-\text { rate })=1-0.2282 \cdot C \text {-rate } \\
& \eta_{D C H}(C-\text { rate })=1-0.6327 \cdot C \text {-rate }
\end{aligned}
$$

Cut-off boundaries can be extracted from the power-dependent charge and discharge curves on given C-rates. An additional safety margin (cut-off voltage at $11.9 \mathrm{~V}$ ) to hinder the deep discharge of the lead-acid battery is included. Boundaries are defined by the following linear equations:

$$
\begin{aligned}
& \text { SoC } C_{\text {cut off }, \mathrm{CH}}(C \text {-rate })=1.1240-1.2757 \cdot C \text {-rate } \\
& \text { SoC } C_{\text {cut off }, \mathrm{DCH}}(C \text {-rate })=0.3070+0.4870 \cdot C \text {-rate }
\end{aligned}
$$

The battery charge and discharge voltages are described by polynomial functions taking the battery power and state of charge into account. The curve fitting with the charge and discharge curves describing the battery voltage for different power and state of charge levels is done using the method of least squares. Battery discharge curves show a linear behavior (in contradiction to charge curves), which makes the quadratic terms dispensable. The voltage is described by the following equations:

$$
\begin{aligned}
& V_{C H}\left(P_{T}, S o C\right)=2.5109 \cdot S_{o C}{ }^{2}-8.7 \cdot 10^{-5} \cdot P_{T}^{2}+0.0093 \cdot S o C \cdot P_{T}-0.9976 \cdot S o C+0.0185 \cdot P_{T}+11.9241 \\
& V_{D C H}\left(P_{T}, S o C\right)=1.2981 \cdot S o C-0.0017 \cdot P_{T}+11.5240
\end{aligned}
$$

with SoC the battery state of charge and $P_{T}$ the battery terminal power in W.

The battery state of charge is defined by a simple energy balance for every simulation step using an off-line bookkeeping method, which is also used by Schmid et al. [36]. It is defined by the following equation:

$$
\operatorname{SoC}(t)=\operatorname{SoC}(t-1)+\frac{\left(P_{T}-P_{\text {loss }, \text { total }}-P_{\text {self-discharge }}\right) \cdot d t}{E_{\text {actual }}}
$$

with Ploss, total the charge and discharge losses in W, Pself-discharge the battery self-discharge power in W (calculated with the relative capacity loss of $1.1421 \cdot 10^{-8} 1 \cdot \mathrm{s}^{-1}$ from the datasheet and the current battery capacity), dt the timestep in hours, and Eactual the current battery capacity in Wh.

\section{Thermal model}

The thermal model follows a simple heat balance integrating the ohmic losses and the convective heat exchange to the environment. The following equation defines the battery temperature in every timestep:

$$
T_{b}(t+1)=\frac{P_{\text {loss }, \text { total }}-h \cdot\left(A \cdot E_{\text {actual }}\right) \cdot\left(T(t)-T_{a}(t)\right) \cdot d t}{\left(m \cdot E_{\text {actual }}\right) \cdot c_{p}}+T(t)
$$


with $\mathrm{h}$ the heat transfer coefficient in $\mathrm{W} \cdot \mathrm{m}^{-2} \cdot \mathrm{K}^{-1}, \mathrm{~A}$ the surface-specific energy $\mathrm{Wh} \cdot \mathrm{m}^{-2}, \mathrm{~m}$ the mass-specific energy in $\mathrm{Wh} \cdot \mathrm{kg}^{-1}$, and $\mathrm{c}_{\mathrm{p}}$ the average battery heat capacity in $\mathrm{J} \cdot \mathrm{kg}^{-1} \cdot \mathrm{K}^{-1}$. Table 3 gives an overview of used battery parameters.

Table 3 Battery thermal model parameter [35].

\begin{tabular}{lll}
\hline Parameter & Unit & Value \\
\hline $\mathrm{h}$ & $\mathrm{W} \cdot \mathrm{m}^{-2} \cdot \mathrm{K}^{-1}$ & 2.0 \\
$\mathrm{~A}$ & $\mathrm{Wh} \cdot \mathrm{m}^{-2}$ & 5843.0 \\
$\mathrm{~m}$ & $\mathrm{Wh} \cdot \mathrm{kg}^{-1}$ & 256.0 \\
$\mathrm{c}_{\mathrm{p}}$ & $\mathrm{J} \cdot \mathrm{kg}^{-1} \cdot \mathrm{K}^{-1}$ & 850.0 \\
\hline
\end{tabular}

\section{Degradation model}

The battery degradation model considers cycle and calendric capacity loss. In case of a power flow, the battery degradation follows the cycle aging model and in case of no power flow, the calendric degradation model is applied.

The cycle aging is based on the lifetime model proposed by Narayan et al. [12] and considers the depth of discharge dependency of the lifetime given in the battery datasheet. The following polynomial approximation function defines the lifetime-depth of discharge correlation and calculates the number of cycles until the end of life:

$$
\text { cycle life }(D o D)=-5168.16 \cdot D o D^{3}+14868.72 \cdot D o D^{2}-15792.13 \cdot D o D+7008.82
$$

To dynamically integrate the capacity degradation Narayan et al. propose the zero-crossing micro-cycle approach. A zero-crossing micro-cycle is defined as the time between two subsequent states where the battery power is zero. After every micro-cycle, its mean depth of discharge is determined and the capacity degradation of this micro-cycle with the given polynomial equations is calculated:

$$
\begin{aligned}
& \overline{D O D}=\frac{\sum_{n=0}^{N} D o D_{i}}{N} \\
& \text { cycle life } e_{\text {micro-cycle }}=\text { cycle life }(\overline{D O D})
\end{aligned}
$$

with the timestep $\mathrm{n}$ to $\mathrm{N}$ and the polynomial function defined in equation (17). The relative and absolute capacity degradation of each micro-cycle are then calculated with the following equations:

$$
\begin{aligned}
& C_{\text {relative loss,micro-cycle }}=\frac{E_{\text {micro-cycle }} /\left(2 \cdot C_{\text {nominal }} \cdot \overline{D O D}\right)}{\text { cycle life } e_{\text {micro-cycle }}} \\
& C_{\text {loss,micro-cycle }}=C_{\text {relative loss,micro-cycle }} \cdot\left(C_{\text {nominal }}-C_{\text {end of life }}\right)
\end{aligned}
$$

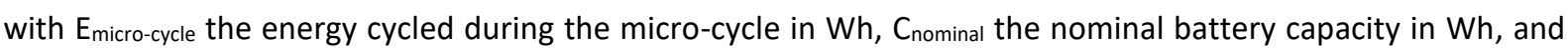
$\mathrm{C}_{\text {end }}$ of life the battery end of life capacity in Wh.

The calendric loss is based on the temperature dependency of the float lifetime given in the battery datasheet. The following equations define the polynomial approximation function for the lifetime in years and the absolute capacity loss per timestep:

$$
\begin{aligned}
& \text { calendric life }\left(T_{b}\right)=7.70 e^{-10} \cdot T_{b}^{-5}+0.0002 \cdot T_{b}^{-5}+33.30 \cdot T_{b}^{-5}-5352.17 \\
& C_{\text {loss,calendric }}=\frac{\left(C_{\text {nominal }}-C_{\text {end of life }}\right)}{\text { calendric life }\left(T_{b}\right) \cdot 8760}
\end{aligned}
$$

\subsubsection{Load profile}

The definition of the load profile is a crucial part of the SHS sizing process [38]. Creating representative load patterns is a complex task due to little knowledge of user behavior and the lack of standard load profiles. Mandelli et al. propose a bottom-up methodology to generate load profiles based on microscopic usage data [39]. Almeida et al. provide average appliance energy consumption for a generic african household with the underlying appliances used [40]. Nevertheless, the load profile is highly dependent on the available appliances and therefore 
from the SHS size category bought. For the current study, three different SHS size categories are considered, according to [5]. These are:

1. Pico System: SHS entry level with typical installed photovoltaic power in the range of 11 to $20.99 \mathrm{Wp}$. Appliances involve lights, radio, and phone chargers. The system enables partial Multi-Tier Framework Tier 1 electricity access.

2. Medium System: SHS with medium capacity with typical installed photovoltaic power in the range of 50-99.99 Wp. Appliances involve Pico System appliances with extended runtime and television. The system enables full Multi-Tier Framework Tier 2 Electricity Access.

3. Large System: SHS with higher capacity with typical installed photovoltaic power higher than $100 \mathrm{Wp}$. Appliances are comparable to Medium system appliances with increased runtime. The system enables full Multi-Tier Framework Tier 2 Electricity Access.

Daily load profiles with an hourly resolution based on typical appliance runtimes given in specification sheets by Lighting Global certified products are generated [7]. Considered appliances (Lights, Radio, Phone charger, TV) show no variable power consumption in a resolution of minutes, as it is the case for fridges or washing machines. Therefore, the used hourly resolution of the simulation can be seen as sufficient.

Table 4 gives an overview of the assumptions made for the profile synthesization, as the number and nominal power of appliances and their usage duration.

Table 4 Load profile synthesization parameter.

\begin{tabular}{llll}
\hline Appliance & Number & Usage duration $[\mathrm{h}]$ & Power [W] \\
\hline Lights & $2 / 8 / 8$ & $13 / 13 / 13$ & $2 / 2 / 2$ \\
Radio & $1 / 1 / 1$ & $3 / 4 / 6$ & $3.5 / 3.5 / 3.5$ \\
Phone charger & $1 / 1 / 1$ & $2 / 3 / 5$ & $5 / 5 / 5$ \\
TV & $0 / 1 / 1$ & $0 / 4 / 6$ & $0 / 15 / 24$ \\
\hline
\end{tabular}

Figure 3 presents the three load profiles generated for the Pico, Medium, and Large System.

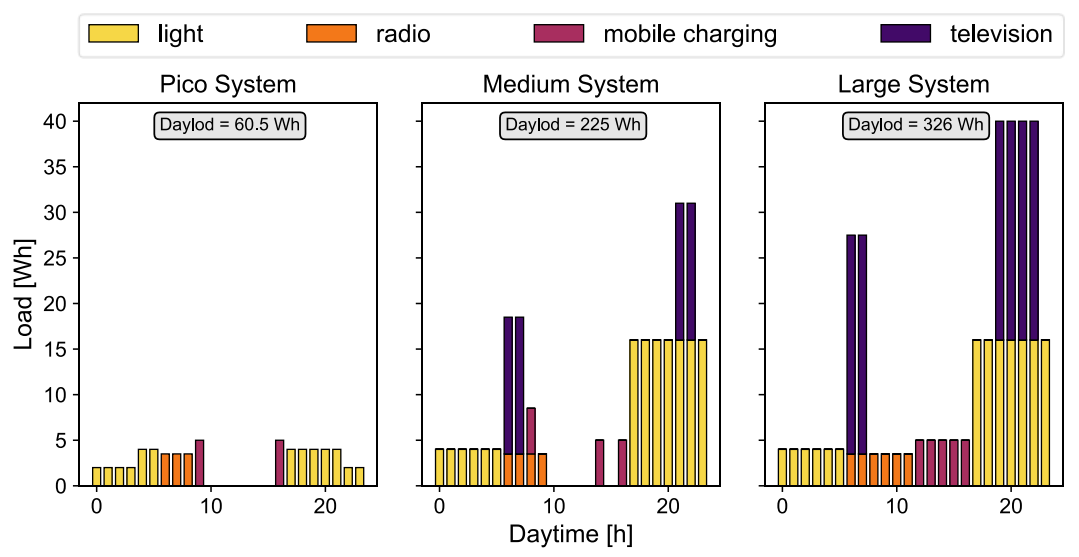

Figure 3 Generated load profiles for all three SHS categories.

The generated load profiles follow the general shape of the load profiles provided by Almeida et al. with the characteristic morning and evening peak [40]. Detailed analysis of the definition of load profiles for SHS is not the subject of this study.

\subsubsection{Meteorological data}

For the consideration of different climatic and irradiance conditions in sub-saharan africa, three case study locations were selected. Case studies are situated in east, west, and central/south africa, which are the main SHS markets in sub-saharan africa [5]. As case studies differ in their geographical location, optimal photovoltaic orientation and tilt angle change as well. Optimal tilt angles according to Jacobson et al. with south orientation for systems situated in the northern hemisphere and north orientation for systems in the southern hemisphere are used [41]. A possible double-sided photovoltaic orientation with south-east and south-west (and north accordingly) orientation, which could improve the share of direct used photovoltaic energy, is neglected. Due to 
the necessary small installed photovoltaic peak power, usually, only one photovoltaic panel is installed, which makes double-sided orientation impossible. The three case studies with its photovoltaic orientation are:

- $\quad$ Porto Novo, Benin $(2.6253,6.4991)$, photovoltaic orientation (south and $10^{\circ}$ inclination)

- Arusha, Tanzania (36.6830, -3.3869), photovoltaic orientation (north and $10^{\circ}$ inclination)

- Upington, South Africa, $(21.2483,-28.4523)$, photovoltaic orientation (north and $26^{\circ}$ inclination)

The irradiance data from the Copernicus Programme Atmosphere Monitoring Service is used. Global, beam, and diffuse irradiance on the horizontal plane is provided in an hourly resolution since 2004 . It is based on the data from geostationary orbit satellites and can be downloaded free of charge [42]. Data on ambient air temperature, humidity, and wind speed is based on the MERRA database provided by the NASA Godard Space Flight Center [43]. For the current study, the timeframe from 01.01 .2010 till 01.01 .2020 with an hourly resolution is used. A brief overview of the main environmental parameters is presented in Table 5.

Table 5 Main environmental parameters of considered SHS locations for the three case studies.

\begin{tabular}{lllll}
\hline Parameter & Unit & Porto Novo & Arusha & Upington \\
\hline Mean irradiation & $\mathrm{kWh} \cdot \mathrm{m}^{-2} \cdot \mathrm{a}^{-1}$ & 1709.13 & 2049.25 & 2214.77 \\
Max irradiance & $\mathrm{W} \cdot \mathrm{m}^{-2}$ & 956 & 1141 & 1208 \\
Mean temperature & $\mathrm{K}$ & 299.6 & 294.8 & 294.0 \\
\hline
\end{tabular}

\subsection{Economic model}

The costs of SHS components in sub-saharan africa vary greatly between different products [3]. Therefore, cost assumptions involve a high degree of uncertainty. In respect to the generic approach of this study, general economic assumptions for the component investment costs (CC), operation and maintenance costs (OMC), and balance of system costs (BOS) are assumed. A correlation between increasing system sizes and lower specific costs per $\mathrm{Wp}$ is neglected because a clear relation is difficult to estimate [3] and only a small photovoltaic panel power range is considered (compare Table 8). PWM investment costs are specified to be $25 \%$ of MPPT investment costs. This is according to the cost relationship of the Victron BlueSolar PWM-Light 10A and the Victron Smartsolar MPPT 75/10 10A charge controller [44], [45]. Further, it is based on personal communication with a SHS manufacturer. Table 6 gives an overview of the economic assumptions made.

Table 6 Cost parameters for the economic model.

\begin{tabular}{llll}
\hline Cost component & Unit & Value & Reference \\
\hline CC Photovoltaic & $\$ \cdot W p^{-1}$ & 1.500 & {$[3]$} \\
CC Battery & $\$ \cdot W h^{-1}$ & 0.208 & {$[3]$} \\
CC MPPT & $\$ \cdot W p^{-1}$ & 0.525 & {$[3],[40]$} \\
CC PWM & $\$ \cdot W p^{-1}$ & 0.131 & {$[44],[45]$} \\
BOS & $\$ \cdot W p^{-1}$ & 1.000 & {$[3]$} \\
OMC & $\% \cdot C^{i}$ & 3.0 & - \\
Annual percentage rate & $\%$ & 5.0 & - \\
\hline
\end{tabular}

As we analyze stand-alone systems for un-productive use in remote areas and no grid-connected SHS, which are more common in areas with unreliable grid connection, we do no consider any backup power source costs (like grid costs or diesel generator costs). Further generators are rare in the analyzed customer segment of SHS but more common in mini-grid applications with an installed power capacity of multiple kilowatts [5].

\subsection{Simulation model}

The numeric power flow simulation follows an object-oriented programming approach and is written in the highlevel language Python ${ }^{\mathrm{TM}}$ 3.7. It is published on GitHub ${ }^{1}$ under the Creative Commons Attribution-ShareAlike 4.0 International License and is developed based on the continuous work on the simulation tool by Schmid et al. [36]. For the current study, the simulation considers a 10-year timeframe with an hourly resolution.

The SHS sizing process aims to find the optimal size of system components under the consideration of environmental and user behavior boundary conditions. For the assessment of system alternatives, different

\footnotetext{
${ }^{1}$ https://github.com/fabmid/Open-Energy-Cell-Simulation
} 
objective functions are used. Objective functions can involve technical, ecological, or economic performance indicators. Khatib et al. provide a detailed overview of objective functions for the sizing of photovoltaic battery standalone systems [46]. In this study, the common key figure LCoE is used for economic quantification. For the determination of energy security, the number of days with PCO is used as a technical indicator.

The LCOE is calculated according to the following equation:

$$
L C o E=\frac{A T L C C}{E_{\text {load supplied }}}=\frac{\sum_{k} A_{c c, k}+A_{\text {omc }, k}+A_{r c, k}+A_{r v, k}}{E_{\text {load supplied }}}
$$

with ATLCC the annual levelized cost flow in $\$ \cdot a^{-1}$, Eload supplied the supplied load energy in Wh, Acc,k the annuity of investment costs of all components $\mathrm{k}$ in $\$ \cdot \mathrm{a}^{-1}$, Aomc,k the annuity of the operation and maintenance costs of all components $\mathrm{k}$ in $\$ \cdot \mathrm{a}^{-1}$, Arc,k the annuity of replacement costs of all components $k$, in case it reaches its end of life in $\$ \cdot a^{-1}$ and $A_{r v, k}$ the residual value of all components $k$. The residual costs of the component $k$ are calculated according to the following equation:

$$
A_{r v, k}=C R F \cdot \frac{S o D_{k, t} \cdot C C_{k, t}}{\left(1+i_{e f f}\right)^{t}}
$$

with CRF the capital recovery factor, So $D_{k, t}$ the state of destruction of the component $k$ at the time $t$ (is zero for a new component and one for an end-of-life component), $\mathrm{CC}_{k, t}$ the investment costs of component $\mathrm{k}$ at the time $t$ and ieff the annual percentage rate. We do not consider any disposal costs for components at their end-of-life as this can not be estimated comprehensibly. It is further questionable if disposal costs occur in cultures and economies of repair, which are in place in sub-saharan africa and have a potential for an alternative approach of solar waste handling [47].

For the technical objective the new figure, the number of days with PCO is considered, which is the mean value of days per year with any power cut-off during the simulation timeframe. This shall reflect the user's perspective in a better way, which sees dominantly the power cut-off and not the amount of energy that is lost.

\subsection{Multi-objective optimization}

In general, a multi-objective optimization seeks the solution of a problem with conflicting objectives. An optimization solution $\mathrm{x}_{1}$ is said to (Pareto)-dominate another solution $\mathrm{x}_{2}$ if it is at least as good as $\mathrm{x}_{2}$ for all the objectives, and strictly better at least for one objective. The set of Pareto optimal solutions is called the Pareto set, while the image of this set is called the Pareto front. The multi-objective optimization procedure aims to approximate the Pareto set by minimizing the distance between the approximation and the Pareto front while presenting a good distribution and wide extent of the Pareto front approximation [48].

The optimization procedure in this study is based on the developed simulation model and the defined objective functions, which shall be minimized. The multi-objective genetic algorithm NSGA II (Non-Sorting Genetic Algorithm) with a posteriori method is implemented according to Deb et al. [49]. The NSGA II seeks for the best approximation of the Pareto set and shows compared to other multiobjective optimization algorithms a good solution distribution and Pareto set approximation [49]. Nevertheless, due to its meta-heuristic characteristic, we refer in the following to the Pareto set/front approximation. Audet et al. review state-of-the-art performance indicators for the Pareto front quality measurement [48]. Authors state that up to date the hypervolume/hyperarea (HV) metrics can be considered as the most relevant one and indicates performance regarding convergence and distribution. To justify the algorithm selection, the NSGA II algorithm is compared with some state-of-the-art genetic algorithms (NSGA III, CMAES, MOEAD, OMOPSO, SPEA2) on the DTLZ2 test problem from Deb et al. [50] with two objectives using the hypervolume/hyperarea as the main performance indicator. Further, the Generational Distance (GD) and Inverted Generational Distance (IGD) are presented, although their significance is limited due to their inability to capture dominance relation [48].

Table 7 Performance indicators of state-of-the-art genetic algorithms [51].

\begin{tabular}{llll}
\hline Algorithm/Indicator & HV & GD & IGD \\
\hline NSGAII & 0.2352 & 0.0026 & 0.0048 \\
NSGAIII & 0.2040 & 0.0118 & 0.0353 \\
CMAES & 0.2073 & 0.0127 & 0.0399 \\
MOEAD & 0.2016 & 0.0135 & 0.0370 \\
OMOPSO & 0.2074 & 0.0139 & 0.0405 \\
\hline
\end{tabular}




\begin{tabular}{llll}
\hline SPEA2 & 0.2360 & 0.0115 & 0.0043 \\
\hline
\end{tabular}

Table 7 presents the results of analyzed performance indicators. The choice of NSGA II is justified by superior values over the compared algorithms for the hyperarea indicator as well as for the Generational Distance and Inverted Generational Distance, which proofs a good Pareto set approximation of NSGA II.

To solve the present multi-objective optimization problem of SHS sizing, Table 8 provides all input and output parameters and data applied. It presents the simulation model inputs, NSGA II algorithm parameter set up, which is defined according to standard values by [49], as well as the decision variables and objective functions with their constraints.

Table 8 Overview of input and output parameters and data of the optimization problem.

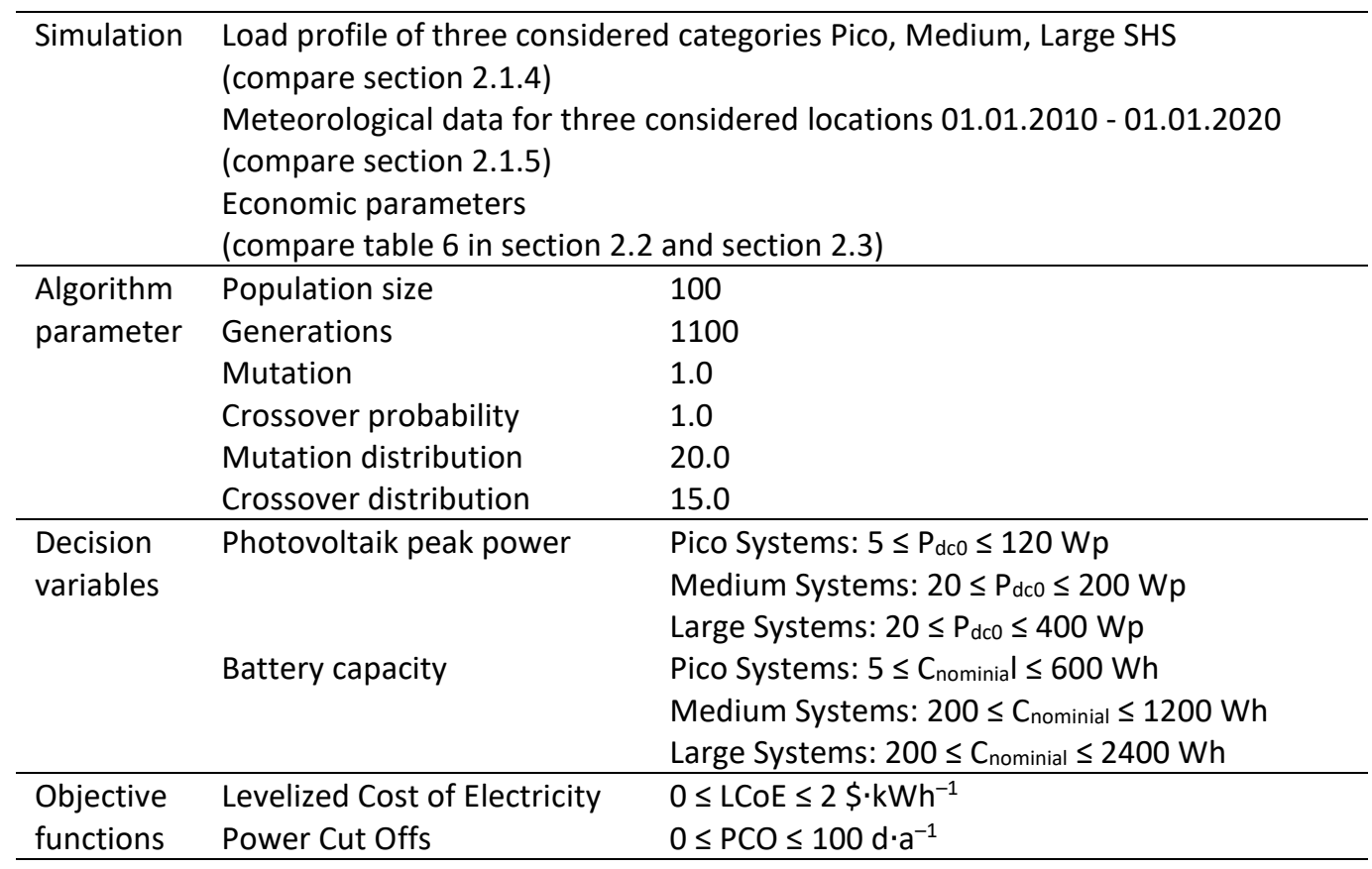

The decision variables cover the photovoltaic peak power and battery capacity, while the charge controller power is sized according to the obtained optimal photovoltaic peak power. Cost savings through an undersizing of the charge controller are neglected and the nominal controller power is fixed to the optimal photovoltaic peak power.

For comparison of different obtained Pareto front approximations, a simple exponential curve fitting $(f(x)=a$. $\left.e^{b \cdot x}\right)$ is applied. As front approximations show a uniform distribution over the objective space, it is assumed that more elaborated methods as curve estimation proposed by Binois et al. are not necessary for this purpose [52], [53].

\subsection{Sensitivity analysis}

In order to analyze the robustness of results of the approximate set of Pareto-optimal solutions, an a-posteriori sensitivity analysis is conducted. The sensitivity of the two objective functions regarding changes of input data is examined. Therefore, the stochastic concept of a Monte Carlo simulation for the evaluation of processorintensive models and their results is applied [54].

Three sensitivity cases, namely irradiance, load, and economic are considered. Therefore, normally distributed random factors with an individual relative standard deviation for the solar irradiance, load profile, PWM, and MPPT investment costs are generated. The solar irradiance is varied for each timestep with a relative standard deviation of $12 \%$ [55]. Annual irradiation level is kept constant at this randomization step and varied in the next step by a relative standard deviation of $1.72 \%$, which is determined by the analysis of the last 10 -year annual irradiance data. Each load profile timestep and the PWM and MPPT charge controller investment costs are randomized with an assumed relative standard deviation of $15 \%$. Charge controller investment costs are varied with individual random factors for MPPT and PWM controller which changes not only the absolute value but also 
the cost ratio of the two technologies. Therefore, irradiance and load are randomized for every timestep, while PWM and MPPT charge controller investment costs for each simulation run, which is repeated for 100 Monte Carlo simulation runs.

\section{RESULTS}

This section presents the main results and discussion of the influence of charge controller technology on optimal SHS sizing. First Pareto front approximations for all considered case studies are examined. Second, a detailed look at Pareto-optimal system configurations with installed photovoltaic peak power and battery capacity is analysed in the same context. Third, the influence of charge controller technology on Peak Sun Hours (PSH) and battery SoC is presented. Finally, a sensitivity analysis shows the influence of different input parameters on system performance metrics.

\subsection{Multi-objective optimization}

Figure 4 shows the obtained Pareto front approximations from the multi-objective optimization for all system sizes with PWM and MPPT charge controller at all considered locations. Pareto front approximations of nondominated solutions are fitted with an exponential function and cost differences between the two fitted fronts are displayed as horizontal bar plots with its mean value as a dashed line. In all cases, a lower LCoE for the same number of PCO is achieved by the implementation of a MPPT charge controller. The difference in cost savings is dependent on the number of PCO, system size, and location. There is no consistent correlation between higher cost savings with decreased or increased number of PCO and with the location and thereby with the irradiance level apparent. But cost savings increase for all locations between the Pico and Medium System for the same number of PCO. Mean cost savings between fitted Pareto front approximations are in the range of $4.2 \%$ to $5.6 \%$ for the Pico System and $8.0 \%$ to $8.6 \%$ for the Medium System. The Large System deviates from this trend with mean cost savings between $4.0 \%$ and $6.5 \%$.
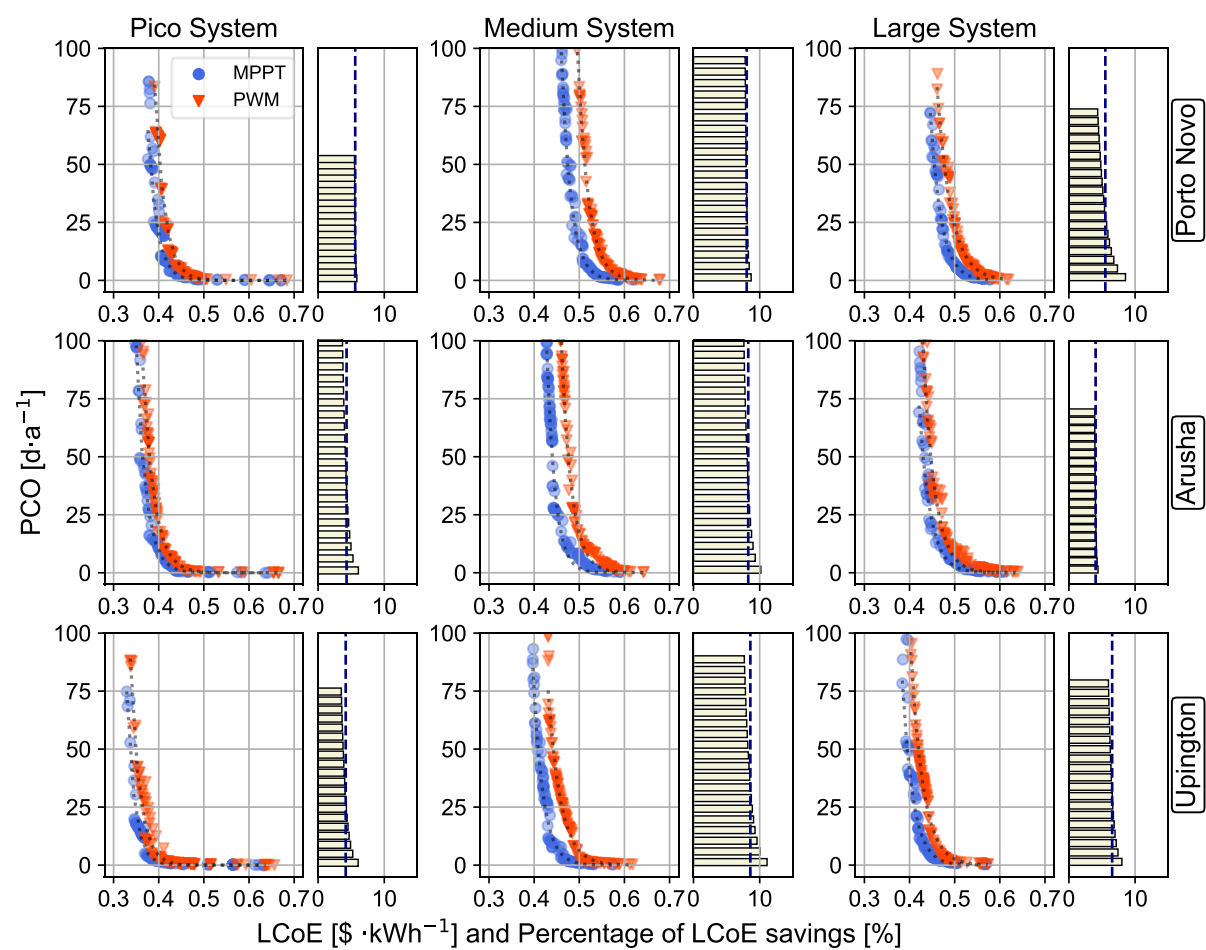

$\mathrm{LCoE}\left[\$ \cdot \mathrm{kWh}^{-1}\right]$ and Percentage of LCoE savings $[\%]$

Figure 4 Pareto front approximations for all system sizes and locations, exponential fitting functions are displayed as dotted black line, cost differences between fitting function of MPPT and PWM fronts are displayed as bar-plot in percentage of LCoE cost savings and its mean value (dashed line).

Figure 5 shows system configurations of the Pareto front approximation for all system sizes at the location Porto Novo. In general, the installed photovoltaic peak power and battery capacity increase towards a smaller number of PCO for all system sizes and independent from the charge controller technology. Systems with a MPPT charge controller show lower installed photovoltaic peak power compared to systems with PWM technology. The mean 
values of the approximate Pareto-optimal solutions with the same number of PCO show a decrease of $34.7 \%$ (Pico System), 38.6 \% (Medium System), and $31.2 \%$ (Large System). Furthermore, charge controller technology shows an influence on the optimal installed battery capacity with slightly lower installed capacities for systems with MPPT compared to PWM. The mean values show a decrease of $8.8 \%$ (Pico System), $5.4 \%$ (Medium System), and $2.8 \%$ (Large System).

As expected, the charge controller technology has a major influence on the approximate Pareto-optimal photovoltaic power installed and main cost savings can be reached through reduced panel sizes. Therefore, higher costs for the MPPT charge controller are mainly balanced by a smaller installed photovoltaic peak power, and even cost savings can be reached. Further, a reduced battery capacity influences the economics of the systems, especially as the battery component is the main cost driver for SHS. In general, the result that relevant cost savings through a MPPT implementation can be reached even for Pico SHS is in contradiction to the assumption in the literature [14].
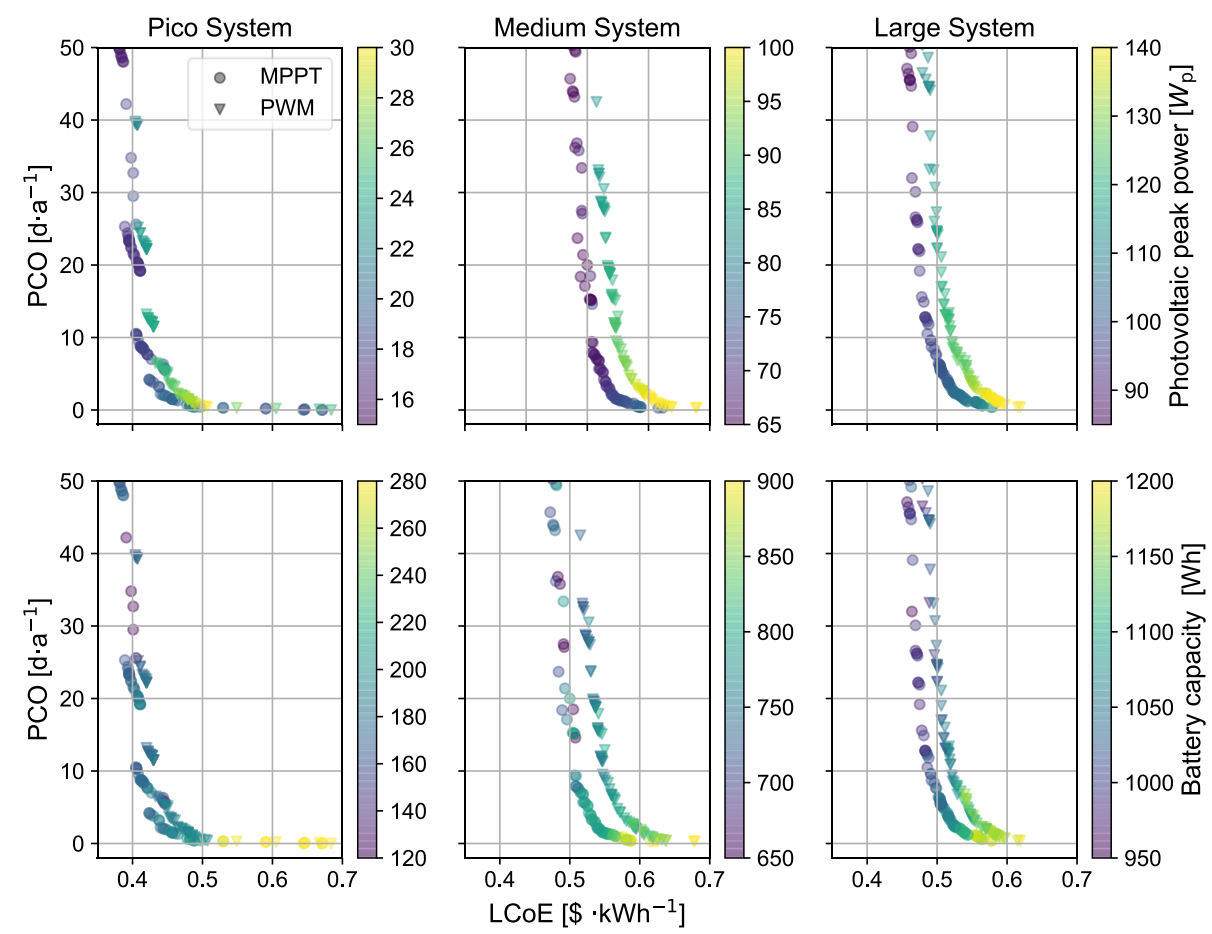

Figure 5 Pareto front approximations with optimal installed photovoltaic peak power and battery capacity for the charge controller technologies PWM and MPPT for all system sizes at the location Porto Novo.

The obtained approximate Pareto-optimal installed photovoltaic peak power for systems with a MPPT charge controller are in good correlation with typical panel sizes of this product category [5]. But it becomes obvious that the information of the implemented charge controller, which is normally not indicated in product brochures (e.g.[7]), is of particular importance to evaluate system capability and sizing.

For the analysis of system capability dependent on the implemented charge controller technology, a Medium Reference System at Porto Novo with $70 \mathrm{Wp}$ installed photovoltaic peak power and $800 \mathrm{Wh}$ battery capacity is analyzed in detail. In the case of an implemented MPPT charge controller, the system shows a PCO of $3 \mathrm{~d} \cdot \mathrm{a}^{-1}$ and lies at the Pareto front approximation. While the same system with PWM shows a PCO of $169 \mathrm{~d} \cdot \mathrm{a}^{-1}$ and is located in the dominated solution space. Figure 6 shows the daily battery state of charge evolution for the 10-year simulation timeframe. The mean state of charge lies with implemented MPPT at a SoC of 0.91, while it is considerably lower at a SoC of 0.56 for an implemented PWM charge controller. To properly assess these results, it should be noted that under no-load operation the minimum SoC lies at 0.3070 (compare equation (11)) and the maximum SoC at 1.1240 (compare equation (12)). The state of charge of the system with an installed PWM charge controller remains low and is often at its discharge cut-off boundary for multiple months (a seasonal effect is apparent). This influences the battery lifetime as a regular full battery charge is necessary to guarantee 
long battery performance and hinder capacity degradation via sulfation and active material softening [10]. The sizing of the battery bank is in strong correlation with the installed photovoltaic peak power. An oversized battery capacity with an undersized photovoltaic power most probably results in faster battery degradation and shorter system lifetimes. On the other side, an undersized battery bank results in regular power cut-offs during night load. Therefore, not only installed photovoltaic peak power and battery capacity is necessary system information but also charge controller technology.
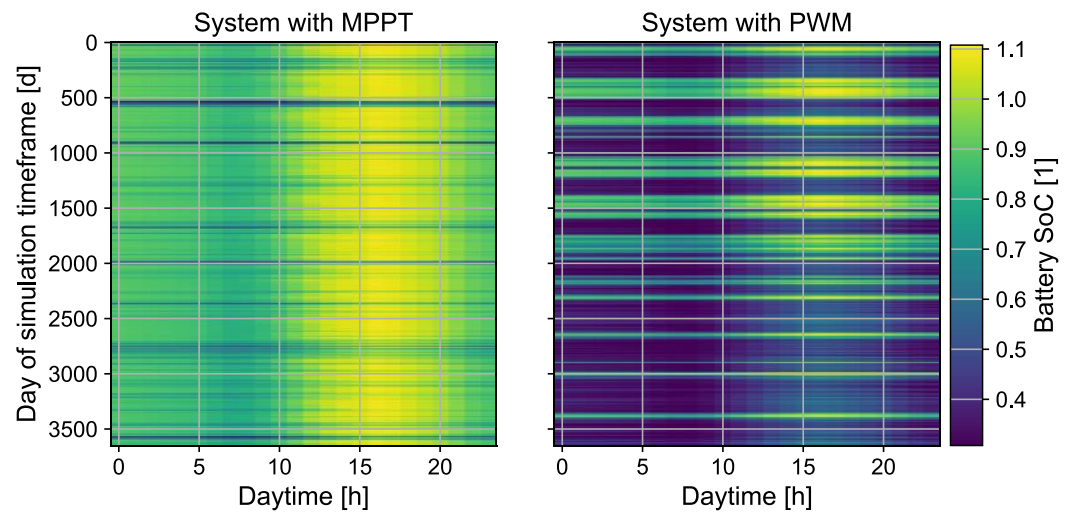

Figure 6 Battery state of charge for a $70 \mathrm{Wp} / 800 \mathrm{Wh}$ system with MPPT and PWM at Porto Novo.

The PSH describe the amount of daily energy yield by the photovoltaic module per installed Wp. The photovoltaic output power (including losses due to inclination and azimuth angle, excluding charge controller losses) is used for the energy yield determination. Figure 7 presents the achieved PSH by using a MPPT and PWM charge controller for the $70 \mathrm{Wp}$ photovoltaic panel at Porto Novo. The MPPT system achieves a mean value of 4.13 Wh. Wp ${ }^{-1}$, while the PWM system lies at $3.52 \mathrm{Wh} \cdot \mathrm{Wp}^{-1}$ (decrease of $14.8 \%$ ). Especially during morning and evening hours the MPPT system can harvest a substantially higher percentage of energy and can generate a photovoltaic current at ambient conditions where the PWM charge controller is unable to do so. This expands the timeframe of direct photovoltaic usage and therefore relieves battery load.
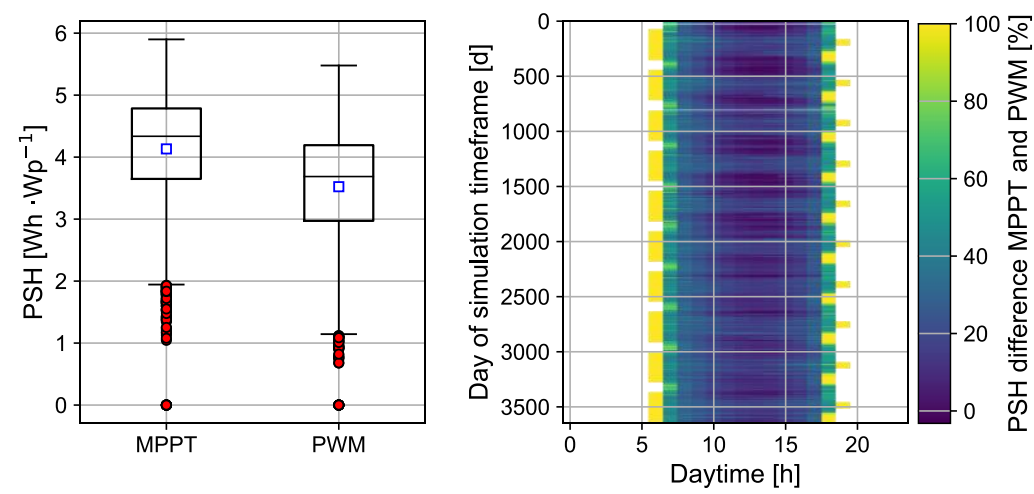

Figure 7 Boxplots of daily PSH of a 70 Wp photovoltaic panel with MPPT and PWM controller at Porto Novo, blue square is indicating the arithmetic mean (left) and hourly PSH difference expressed as percentage over the daytime (right).

In general, it can be stated, that the implementation of a MPPT charge controller increases the system energy efficiency and reduces the resource consumption through smaller system components for all considered SHS size categories.

\subsection{Sensitivity analysis}

A sensitivity analysis is conducted for approximate Pareto-optimal MPPT and PWM Medium Systems at the location Porto Novo. System sizing is done according to the obtained Pareto-optimal approximate solutions with a PCO of $3 \mathrm{~d} \cdot \mathrm{a}^{-1}$. The MPPT system shows $70 \mathrm{Wp}$ and $800 \mathrm{Wh}$ with a LCoE of $0.535 \$ \cdot \mathrm{kWh}^{-1}$, while the PWM system shows $97 \mathrm{Wp}$ and $840 \mathrm{Wh}$ with a LCoE of $0.588 \$ \cdot \mathrm{kWh}^{-1}$ (compare Figure 5).

Figure 8 shows all Monte Carlo simulation runs for the variation of solar irradiance, load profile, and economic investment costs of PWM and MPPT charge controller. The variation of the solar irradiance level shows mainly influence on the PCO, while the LCoE for systems with MPPT and PWM and the identified cost savings remain 
constant. LCoE and PCO show high sensitivity regarding the load profile, with a brought variation on both parameters. But cost savings remain quite constant for all simulation runs with the same number of PCO. As expected, a variation of the economic parameter PWM and MPPT investment costs show no influence on PCO but LCoE. The mean cost savings of all simulation runs remain constant, while the LCoE differs for individual runs.
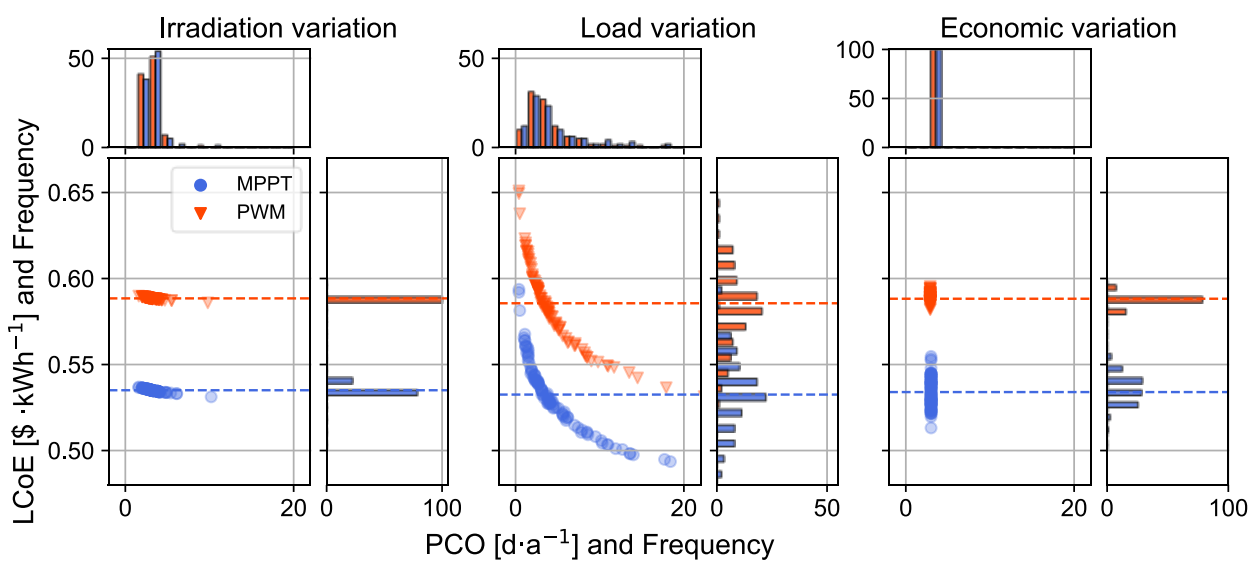

Figure 8 Monte Carlo simulation results for the sensitivity cases irradiance, load and economic. Scatter plots present obtained values of LCOE and PCO, while histograms present their distribution with the frequency as number of cases. Dashed line is representing LCoE arithmetic mean off all Monte Carlo simulation runs.

Figure 9 represents the LCOE cost savings dependent on generated random factors for the variation of PWM and MPPT investment costs. Mean cost savings are at $10.1 \%$, which is in the range of the obtained cost savings identified by the difference in Pareto front approximations (compare Figure 4). Cost savings are more dependent on the variation of MPPT costs than PWM costs and decrease with an increase in the random factor for MPPT investment costs. This can be explained through the fact, that investment costs for a MPPT charge controller are higher than for a PWM charge controller, but both are assumed to have the same relative standard deviation. Therefore, MPPT costs increase stronger than PWM costs. In this context, it needs to be mentioned that photovoltaic investment costs are likely to be lower for panels with higher maximum power voltage than considered in this study, which were specifically identified for the usage with PWM charge controllers. This is supported by Müller et al., who state that a wider choice of photovoltaic panels can be used in combination with an MPPT [15]. These potential cost savings are therefore untracked in this methodology and could further reduce the overall cost difference of these two systems.

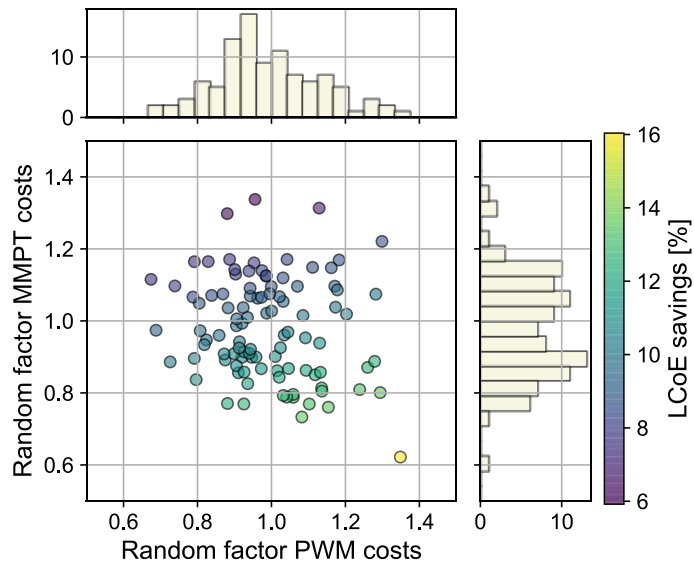

Figure 9 Monte Carlo simulation results for the economic sensitivity case with random factor generation for PWM and MPPT charge controller costs and its influence on LCoE cost savings between systems with MPPT and PWM.

In general, it can be stated that LCOE cost savings are robust regarding the variation of solar irradiance and load profile and investment costs of charge controller technologies. 


\section{CONCLUSION}

In this study, the influence of MPPT and PWM charge controller technologies on Pareto-optimal SHS sizing was examined using a numerical power flow simulation and multi-objective optimization with the objective functions PCO and LCoE. Three different SHS sizes at three case studies in sub-saharan africa were analyzed using a 10year simulation timeframe with an hourly resolution. Through the implementation of a MPPT charge controller mean LCoE savings in the range of $4.0 \%$ to $8.6 \%$ could be identified dependent on system size and location. Higher charge controller costs can be saved by reduced necessary photovoltaic peak power (by $31.2 \%$ to $38.6 \%$ ) and battery capacity (by $2.8 \%$ to $8.8 \%$ ). It is shown that the use of MPPT charge controllers increases energy efficiency, reduces resource consumption through reduced system component sizes, and shows a promising solution to reduce system costs, even for the smallest SHS sizes.

These results have a high significance for optimal SHS design, as they are contrary to the often-applied practical statement, that PWM charge controllers are advantageous for smaller system sizes. The Monte Carlo simulation shows the robustness of obtained LCoE cost savings regarding the variation of solar irradiance, load profile, and charge controller investment costs. The highest influence on cost savings reveals the investment cost assumptions with savings between $6 \%$ and $16 \%$ at a mean value of $10.1 \%$. Further, the presented influence of charge controller technology on the expectable PSH and battery state of charge highlights the lack of controller technology specification on most system datasheets. SHS manufacturers withhold customers valuable information to assess the full system capability.

Even significantly higher MPPT investment costs than PWM costs cannot balance out the identified cost savings. But it needs to be stated, that the general economic assumption made in this study, may not represent universal real-life component costs and should be adapted to specific cases. Therefore, this study gives SHS manufacturers the basis for a case-specific analysis of whether the use of MPPT controllers can be not only technical but also economically advantageous.

Future research should focus on the influence of different cost assumptions on the system economics and involve site-specific economic values to reduce the uncertainty of these parameters. The authors strive for cooperation with a SHS manufacturer to apply developed methods to real-life cases. The developed numeric simulation tool can be used for such future research as it is open-source and models can be easily parameterized with datasheet data. In general, this can help to improve SHS sizing in the practical field, guarantee optimal system performance and lifetime, as well as provide technology decision support.

\section{ACKNOWLEDGEMENTS}

The authors thank Jenny Rieck for methodological and content-related support. This research did not receive any specific grant from funding agencies in the public, commercial, or not-for-profit sectors. 


\section{REFERENCES}

[1] IEA, IRENA, UNSD, World Bank, and WHO, 'Tracking SDG 7: The Energy Progress Report'. Washington DC, 2020.

[2] Lighting Global, 'Why Off-Grid Energy?', 2020. [Online]. Available: https://www.lightingglobal.org/about/why-off-grid-energy/. [Accessed: 24-Jul-2020].

[3] IRENA, Solar PV in Africa: Costs and Markets. 2016.

[4] Financial Times, 'Leapfrogging into the light', 2017. [Online]. Available: https://www.ft.com/content/41524878-108f-11e7-b030-768954394623. [Accessed: 24-Jul-2020].

[5] World Bank Group and Lighting Global, 'Off-Grid Solar Market Trends Report 2020', 2020.

[6] International Electrotechnical Comision, 'Standard IEC TS 62257-9-5:2018 - Recommendations for renewable energy and hybrid systems for rural electrification - Part 9-5: Integrated systems Laboratory evaluation of stand-alone renewable energy products for rural electrification'. 2018.

[7] Lighting Global, 'Product Certification', 2020. [Online]. Available: https://www.lightingglobal.org/products/. [Accessed: 15-Jul-2020].

[8] R. G. Charles, M. L. Davies, P. Douglas, I. L. Hallin, and I. Mabbett, 'Sustainable energy storage for solar home systems in rural Sub-Saharan Africa - A comparative examination of lifecycle aspects of battery technologies for circular economy, with emphasis on the South African context', Energy, vol. 166, pp. 1207-1215, 2019.

[9] Shell Foundation, 'Energy storage trends for off - grid services in emerging markets', 2018.

[10] G. J. May, A. Davidson, and B. Monahov, 'Lead batteries for utility energy storage: A review', J. Energy Storage, vol. 15, pp. 145-157, 2018.

[11] D. U. Sauer and H. Wenzl, 'Comparison of different approaches for lifetime prediction of electrochemical systems-Using lead-acid batteries as example', J. Power Sources, vol. 176, no. 2, pp. 534-546, 2008.

[12] N. Narayan et al., 'Estimating battery lifetimes in Solar Home System design using a practical modelling methodology', Appl. Energy, vol. 228, no. March, pp. 1629-1639, 2018.

[13] M. A. Laguado, E. Andres, L. Paipa, and S. Sepulveda, 'Performance comparison between PWM and MPPT charge controllers', 2019.

[14] Victron Energy, 'Which solar charge controller: PWM or MPPT?', 2020.

[15] M. Müller, R. Bründlinger, O. Arz, W. Miller, J. Schulz, and G. Lauss, 'PV-off-grid hybrid systems and MPPT charge controllers, a state of the art analyses', Energy Procedia, vol. 57, no. December, pp. 14211430, 2014.

[16] P. E. Campana et al., 'An open-source optimization tool for solar home systems: A case study in Namibia', Energy Convers. Manag., vol. 130, pp. 106-118, 2016.

[17] F. Rossi, M. Heleno, R. Basosi, and A. Sinicropi, 'Environmental and economic optima of solar home systems design: A combined LCA and LCC approach', Sci. Total Environ., vol. 744, p. 140569, 2020.

[18] T. Khatib and D. H. Muhsen, 'Optimal sizing of standalone photovoltaic system using improved performance model and optimization algorithm', Sustain., vol. 12, no. 6, 2020.

[19] N. Narayan et al., 'Exploring the boundaries of Solar Home Systems (SHS) for off-grid electrification: Optimal SHS sizing for the multi-tier framework for household electricity access', Appl. Energy, vol. 240, no. February, pp. 907-917, 2019.

[20] M. R. Chen, G. Q. Zeng, and K. Di Lu, 'A many-objective population extremal optimization algorithm with an adaptive hybrid mutation operation', Inf. Sci. (Ny)., vol. 498, pp. 62-90, 2019.

[21] M. R. Chen, G. Q. Zeng, and K. Di Lu, 'Constrained multi-objective population extremal optimization based economic-emission dispatch incorporating renewable energy resources', Renew. Energy, vol. 143, pp. 277-294, 2019.

[22] 'pvlib python documentation', 2020. [Online]. Available: https://pvlibpython.readthedocs.io/en/stable/index.html. [Accessed: 27-Jul-2020].

[23] Sollarhub, 'PV Module Midi PVGU Window Details'. [Online]. Available: http://www.solarhub.com/product-catalog/pv-modules/46663-Midi-PVGU-Window-Pythagoras-Solar. [Accessed: 17-Jul-2020].

[24] Solarhub, 'PV Module CS5C-80M'. [Online]. Available: http://www.solarhub.com/product-catalog/pvmodules/104-CS5C-80M-Canadian-Solar. [Accessed: 17-Jul-2020].

[25] Solarhub, 'PV Module EPML120W6H'. [Online]. Available: http://www.solarhub.com/productcatalog/pv-modules/6208-EPML120W6H-Resonix. [Accessed: 17-Jul-2020].

[26] National Renewable Energy Laboratory, 'System Advisor Model libaries', 2020. [Online]. Available: https://github.com/NREL/SAM/tree/develop/deploy/libraries. [Accessed: 22-Sep-2020]. 
[27] W. De Soto, S. A. Klein, and W. A. Beckman, 'Improvement and validation of a model for photovoltaic array performance', Sol. Energy, vol. 80, no. 1, pp. 78-88, 2006.

[28] P. Gilman, 'SAM Photovoltaic Model Technical Reference SAM Photovoltaic Model Technical Reference', 2018.

[29] A. P. Dobos, 'PVWatts Version 5 Manual (NREL/TP-6A20-62641)', Natl. Renew. Energy Lab., no. September, p. 20, 2014.

[30] D. L. King, W. E. Boyson, and J. A. Kratochvill, 'Photovoltaic Array Performance Model', Albuquerque, New Mexico, 2004.

[31] J. Linssen, P. Stenzel, and J. Fleer, 'Techno-economic analysis of photovoltaic battery systems and the influence of different consumer load profiles', Appl. Energy, vol. 185, pp. 2019-2025, 2015.

[32] D. U. Sauer and H. Schmidt, 'Praxisgerechte Modellierung und Abschätzung von WechselrichterWirkungsgraden', in 9. Internationales Sonnenforum - Tagungsband I, 1994, pp. 550-557.

[33] High Quality Solar Technology, 'HQST MPPT Solar Charge Controller User Manual', 2017.

[34] ACOPOWER, 'HY-MPPT Series MPPT Solar Charge Controller - User Manual', 2018. [Online]. Available: https://images-na.ssl-images-amazon.com/images/I/B1F0uiO8QaS.pdf. [Accessed: 30-Jun-2020].

[35] Ritar, 'Battery datasheet Ritar OPzV12-100 (12V 100Ah)', 2017.

[36] F. Schmid, J. Winzer, A. Pasemann, and F. Behrendt, 'An open-source modeling tool for multi-objective optimization of renewable nano/micro-off-grid power supply system: Influence of temporal resolution, simulation time, and location', Energy, vol. 219, 2021.

[37] O. Tremblay, L. Dessaint, and A. Dekkiche, 'A Generic Battery Model for the Dynamic Simulation of Hybrid Electric Vehicles', IEEE, pp. 284-289, 2007.

[38] S. Mandelli, C. Brivio, E. Colombo, and M. Merlo, 'Effect of load profile uncertainty on the optimum sizing of off-grid PV systems for rural electrification', Sustain. Energy Technol. Assessments, vol. 18, pp. 34-47, 2016.

[39] S. Mandelli, M. Merlo, E. Colombo, M. Moncecchi, and F. Riva, 'Novel procedure to formulate load profiles for off-grid rural areas - the Load Pro Gen software', in Energy for Sustainable Development, 2016, vol. 31, pp. 1-8.

[40] A. De Almeida and P. Moura, 'Energy-efficient off-grid systems-review', pp. 349-376, 2020.

[41] M. Z. Jacobson and V. Jadhav, 'World estimates of PV optimal tilt angles and ratios of sunlight incident upon tilted and tracked PV panels relative to horizontal panels', Sol. Energy, vol. 169, no. April, pp. 5566, 2018.

[42] Solar radiation Data (SoDa), 'CAMS Radiation Service HelioClim-3 time series data'. [Online]. Available: http://www.soda-pro.com/web-services/radiation/cams-radiation-service/info. [Accessed: 01-Jul2020].

[43] Global Modeling and Assimilation Office (GMAO), 'MERRA-2 tavg1_2d_slv_Nx: 2d,1-Hourly,TimeAveraged,Single-Level,Assimilation,Single-Level Diagnostics V5.12.4', 2015. .

[44] offgridtec - autarkic energy for everybody, 'Victron BlueSolar PWM-Light 12V 24V 10A Solar Charge Controller', 2020. [Online]. Available: https://www.offgridtec.com/en/victron-bluesolar-pwm-light-12v24v-10a-solar-laderegler.html. [Accessed: 22-Sep-2020].

[45] offgridtec - autarkic energy for everybody, 'Victron Smartsolar MPPT 75/10 10A 12V 24V controller', 2020. [Online]. Available: https://www.offgridtec.com/en/victron-smartsolar-mppt-75-10-10a-12v-24vsolar-laderegler.html. [Accessed: 22-Sep-2020].

[46] T. Khatib, I. A. Ibrahim, and A. Mohamed, 'A review on sizing methodologies of photovoltaic array and storage battery in a standalone photovoltaic system', Energy Convers. Manag., vol. 120, pp. 430-448, Jul. 2016.

[47] J. Cross and D. Murray, 'The afterlives of solar power: Waste and repair off the grid in Kenya', Energy Res. Soc. Sci., vol. 44, no. August 2017, pp. 100-109, 2018.

[48] C. Audet, J. Bigeon, D. Cartier, S. Le Digabel, and L. Salomon, 'Performance indicators in multiobjective optimization', Eur. J. Oper. Res., pp. 1-39, 2020.

[49] K. Deb, A. Member, A. Pratap, S. Agarwal, and T. Meyarivan, 'A fast and elitist multi-objective genetic algorithm: NSGAII', IEEE Trans. Evol. Comput., vol. 6, no. 2, pp. 182-197, 2002.

[50] K. Deb, L. Thiele, M. Laumanns, and E. Zitzler, 'Scalable multi-objective optimization test problems', Proc. 2002 Congr. Evol. Comput. CEC 2002, vol. 1, no. June, pp. 825-830, 2002.

[51] D. Hadka, 'MOEA Framework: A Free and Open Source Java Framework for Multiobjective Optimization'. 2014.

[52] M. Binois, D. Rullière, and O. Roustant, 'On the estimation of Pareto fronts from the point of view of copula theory', Inf. Sci. (Ny)., vol. 324, pp. 270-285, 2015.

[53] M. Binois, D. Ginsbourger, and O. Roustant, 'Quantifying uncertainty on Pareto fronts with Gaussian 
process conditional simulations', Eur. J. Oper. Res., vol. 243, no. 2, pp. 386-394, 2015.

[54] C. Physics, 'Sensitivity analysis in the context of uncertainty analysis for computationally intensive models', Comput. Phys. Commun., vol. 7, pp. 21-34, 1999.

[55] C. R. Björn Müller, Laura Hardt, Alfons Armbruster, Klaus Kiefer, 'Yield predictions for photovoltaic power plants: empirical validation, recent advances and remaining uncertainties', Prog.

PHOTOVOLTAICS Res. Appl., no. 24, pp. 570-583, 2016. 